\title{
CD10 protein expression in tumor and stromal cells of malignant melanoma is associated with tumor progression
}

\author{
Nurija Bilalovic ${ }^{1}$, Berit Sandstad ${ }^{2}$, Rastko Golouh ${ }^{3}$, Jahn M Nesland ${ }^{4}$, Ivan Selak ${ }^{1}$ and \\ Emina E Torlakovic ${ }^{4}$ \\ ${ }^{1}$ Department of Pathology, University Hospital Sarajevo, Bosnia and Herzegovina; ${ }^{2}$ Clinical Research Office, \\ The Norwegian Radium Hospital, Oslo, Norway; ${ }^{3}$ Department of Pathology, Institute of Oncology, Ljubljana, \\ Slovenia and ${ }^{4}$ Department of Pathology, The Norwegian Radium Hospital, University of Oslo, Montebello, \\ Oslo, Norway
}

\begin{abstract}
CD10 antigen is a 100-kDa-cell surface zinc metalloendopeptidase expressed in a variety of normal and neoplastic lymphoid and nonlymphoid tissues including melanomas. It was recently shown that metastatic melanomas express more CD10 than primary tumors. We evaluated CD10 expression in tumor and stromal cells in 70 biopsies with primary and 28 with metastatic malignant melanomas. $\mathrm{Ki}-67, \mathrm{Bcl}-2$, and Bax were also examined to investigate whether CD10 expression is associated with tumor proliferation index or factors of apoptosis. Formalin-fixed/paraffin-embedded tissues were studied by immunohistochemistry. More advanced primary tumors had higher CD10 expression in the tumor cells $(r=0.27, P=0.03$ for Clark levels and $r=0.29$, $P=0.02$ for Breslow) and higher Ki-67 proliferation fraction $(r=0.32, P=0.007$ for Clark levels and $r=0.32$, $\boldsymbol{P}=0.001$ for Breslow). Similarly, CD10 expression in the intratumoral stromal cells was also higher in primary tumors with higher Clark level $(P=\mathbf{0 . 0 4}$, linear-by-linear association) and tumor thickness according to Breslow $(r=0.33, P=0.01)$. The presence of $\mathrm{CD} 10+$ peritumoral stromal cell cuffs was also positively associated with tumor thickness according to Breslow $(r=0.27, P=0.05)$. Also, expression of CD10 and $\mathrm{Ki}-67$ were significantly higher in metastatic than in primary tumors $(P=0.01$ and 0.02 respectively), but $\mathrm{Bcl}-2$ expression was higher in primary melanomas $(P=0.02)$. We conclude that $C D 10$ expression in malignant melanoma is associated with tumor progression.
\end{abstract}

Modern Pathology (2004) 17, 1251-1258, advance online publication, 18 June 2004; doi:10.1038/modpathol.3800174

Keywords: malignant melanoma; CD10; Ki-67; Bcl-2; Bax; tumor thickness (Breslow); depth of invasion (Clark)

The biology and natural history of melanocytic tumors are still incompletely understood. Several clinical and routine histological factors of primary melanomas with prognostic significance have been described, that is, tumor thickness according to Breslow, Clark levels, ulceration, localization, presence of tumor-infiltrating lymphocytes, gender, and patients' age. ${ }^{1}$ By far, the most significant and consistent prognostic factor in all series over the past 20 years is Breslow thickness of the primary melanoma. ${ }^{2}$ Kanitakis et $a l^{3}$ have recently found that CD10 is more frequently expressed in metastatic

Correspondence: Dr EE Torlakovic, MD, Department of Pathology, The Norwegian Radium Hospital, University of Oslo, Montebello, Oslo 0310, Norway.

E-mail: emina.torlakovic@labmed.uio.no

Received 18 August 2003; revised 1 December 2003; accepted 5 December 2003; published online 18 June 2004 than in primary melanoma. Carrel et $a l^{4}$ also found that CD10 expression in melanoma cells is higher in primary tumors larger than $3 \mathrm{~mm}$.

CD10 is a $90-110-k D a$ cell surface zinc-dependent metalloprotease that has been called neutral endopeptidase, enkephalinase, neprilysin, and common acute lymphoblastic leukemia antigen. Besides hematopoietic tissue, various benign and malignant nonhematopoietic tissues were also found to express CD10. ${ }^{5-10}$ CD10 is known to regulate biological activities of peptide substrates by reducing the local concentrations available for receptor binding and signal transduction. ${ }^{11}$ CD10 may also play an important role in maintenance of homeostasis, neoplastic transformation, and tumor progression. ${ }^{12-14}$ Recent works suggested that CD10 expression in cancer cells could have a role both in apoptosis and proliferation, ${ }^{15-17}$ while CD10 expression in intratumoral stromal cells may also contribute to tumor progression. ${ }^{18}$ 
Programmed cell death, apoptosis, is a physiological mechanism of cell death that plays an important role during development, metamorphosis, and organ involution in many diseases, including cancer. ${ }^{19}$ Regulation of apoptosis is a complex process and involves a number of genes, including Bcl-2, Bax, and related family members. ${ }^{19-21} \mathrm{Bcl}-2$, the protein product of the $B c l-2$ gene, is a member of the Bcl-2 family of proteins that play a crucial role in a complex mechanism of apoptosis. The Bcl-2 family is divided into two subfamilies: the proapoptotic family (ie Bax, Bak, Bik, Bad), which induce apoptosis, and the antiapoptotic family (ie Bcl-2, Bcl- $\mathrm{x}_{\mathrm{L}}$, Bcl-w), which protect cells from apoptosis. ${ }^{22}$ Bax gene product, an intracellular partner of Bcl-2, first identified by coimmunoprecipitation with $\mathrm{Bcl}-2$, is a $21-\mathrm{kDa}$ protein with $21 \%$ homology to Bcl-2. Expression of Bax does not block apoptosis; instead, it seems to inhibit Bcl-2 function, perhaps by forming Bcl-2/Bax heterodimers or by competing with other Bcl-2 target. ${ }^{23}$ It is suggested that the Bcl-2/Bax ratio may be important in regulating the nature of the apoptotic response; if Bax predominates, apoptosis is accelerated, and the antiapoptotic activity of Bcl-2 is antagonized.

Expression of Bcl-2 family members in melanoma metastases, primary melanomas, naevi and normal tissue samples has been described, ${ }^{24-27}$ but seems to be somewhat controversial as both overexpression and reduced expression have been reported. ${ }^{28}$ Their role in the process of malignant transformation of melanocytes has been questioned. No prognostic value of Bcl-2 expression was found by Loggini et $a l ;{ }^{29}$ however, a strong indication of a correlation between tumor thickness and Bcl-2 expression in nodular malignant melanomas has also been reported. ${ }^{30}$ Our study explores CD10 expression in primary and metastatic melanoma and its association with proliferation rate (Ki-67) and expression of Bcl-2 and Bax.

\section{Materials and methods}

We studied formalin-fixed, paraffin-embedded tissue sections from 70 primary and 28 metastatic melanomas that were randomly collected from the archives of the pathology department, The Norwegian Radium Hospital. The median age of the patients was 62 years (range 19-93 years). Of the primary tumors, 53 were classified as superficial spreading and 17 as nodular. Distribution of Clark levels was as follows: $19 \%$ were Clark I, 36\% Clark II, $23 \%$ Clark III, and $22 \%$ Clark IV. The primary tumor thickness median was $1.50 \mathrm{~mm}$ (range 0.30 $7.00 \mathrm{~mm}$ ).

\section{Immunohistochemistry}

Formalin-fixed, paraffin-embedded tissue was cut at $5 \mu \mathrm{m}$, dried overnight at $60^{\circ} \mathrm{C}$ and deparaffinized in xylene. Subsequently, the sections were rehydrated through graded alcohols into water. Heat-induced epitope retrieval was achieved by boiling sections in the EDTA buffer at $\mathrm{pH} 8.9$ in the Electrolux microwave oven (Stockholm, Sweden) at $1000 \mathrm{~W}$ for $20 \mathrm{~min}(4 \times 5 \mathrm{~min})$. After boiling, the sections were allowed to cool at room temperature for $20 \mathrm{~min}$, rinsed thoroughly with water and placed in Tris-buffered saline (TBS) for $5 \mathrm{~min}$. Endogenous peroxidase was blocked with peroxidase block solution provided in the EnVison $+{ }^{\circledR}$ kit (DakoCytomation, Glostrup, Denmark) for $5 \mathrm{~min}$ and slides rinsed/washed with TBS. Primary antibodies used in the study are listed in Table 1. The visualization was performed using EnVision $+{ }^{\mathbb{R}}$ (DakoCytomation, Glostrup, Denmark) method according to the manufacturer's instructions. Appropriate positive and negative controls were used. Expression of CD10, Bcl-2, and Bax in the tumor cells was quantified using H-score (histoscore) system, according to the method described by McCarty Jr et $a l,{ }^{31}$ which considers both the intensity and percentage of cells staining at each intensity. Cells are counted by using $\times 400$ magnification and a cell counter. The score was calculated as follows: $\mathrm{H}$-score $=(\% 3+$ cells $\times 3)+(\% 2+$ cells $\times 2)+(\% 1+$ cells $\times 1)$. Ki-67 proliferation fraction was determined by counting the percent of the positive cells in 400 cells using a cell counter. CD10 expression in intratumoral fibroblast-like cells and peritumoral fibroblast-like cells was evaluated only in the primary tumors. The number of positive cells was visually estimated and stratified into four groups $(0=$ negative, $1=$ weakly, $2=$ moderate, and $3=$ strong expression).

\section{Statistical Methods}

Differences in antigen expression between primary and metastatic tumors were analyzed with the Mann-Whitney $U$-test. The association between the intensity of expression with depth of invasion (Clark levels); tumor thickness according to Breslow and diameter of tumors was studied with the

Table 1 Primary antibodies

\begin{tabular}{|c|c|c|c|}
\hline $\begin{array}{l}\text { Antibody } \\
\text { (clone) }\end{array}$ & Dilution & $\begin{array}{l}\text { Incubation } \\
\text { time (Temp.) }\end{array}$ & Source \\
\hline CD10 (56C6) & $1: 150$ & $\begin{array}{l}\text { Overnight } \\
\qquad\left(4^{\circ} \mathrm{C}\right)\end{array}$ & $\begin{array}{l}\text { Novocastra } \\
\text { Laboratories, } \\
\text { New Castle upon Tyne, } \\
\text { UK }\end{array}$ \\
\hline Ki-67 (MIB1) & $1: 100$ & $30 \min (\mathrm{RT})$ & $\begin{array}{l}\text { DakoCytomation, } \\
\text { Glostrup, Denmark }\end{array}$ \\
\hline $\begin{array}{l}\text { Bcl-2 (124- } \\
\text { BCL-2) }\end{array}$ & $1: 20$ & $30 \min (\mathrm{RT})$ & $\begin{array}{l}\text { DakoCytomation, } \\
\text { Glostrup, Denmark }\end{array}$ \\
\hline Bax (2D2) & $1: 150$ & $30 \min (\mathrm{RT})$ & $\begin{array}{l}\text { NeoMarkers, Fremont, } \\
\text { USA }\end{array}$ \\
\hline
\end{tabular}

$\mathrm{RT}=$ room temperature. 
Spearman rank correlation. Linear-by-linear association test was used when appropriate. Statistical significance was established at the $P<0.05$ level. Analyses were performed in SPSS 11.5.

\section{Results}

Association between Primary Melanoma Size and Expression of CD10, Bcl-2, Bax, and Ki-67 Proliferation Fraction

Distribution of H-scores for CD10, Bcl-2, and Bax is given in Table 2. The results of CD10 expression and Ki-67 expression are illustrated in Figure 1a-f. CD10 expression in primary melanomas as evaluated by H-score is detailed in Table 3 . When $10 \%$ cutoff point was used, $22 \%(16 / 70)$ of primary tumors showed CD10 expression in melanoma cells. CD10 expression was significantly higher in primary tumors with higher Clark level $(r=0.27 ; P=0.03)$ and larger tumor thickness according to Breslow $(r=0.29 ; P=0.02)$ (Figures $1 \mathrm{a}$ and $\mathrm{b}$ and $2 \mathrm{a}$ and $\mathrm{b})$. Strong CD10 expression in the intratumoral fibroblast-like stromal cells was found in $70 \%$ of the primary tumors (Figure 1e). Also, CD10 expression in the intratumoral stromal cells was higher in higher Clark levels $(P=0.04$, linear-by-linear association) as well as in the tumors with larger thickness according to Breslow $(P=0.01, r=0.33)$. $\mathrm{CD} 10+$ fibroblast-like stromal cells forming a peritumoral cuff were found in $44 \%$ of the primary tumors (Figure 1f). The formation of the CD10+ peritumoral cuff was showed a statistical trend for positive association with larger tumor thickness according to Breslow $(P=0.05, r=0.27)$. The percentage of Ki-67-positive cells was significantly higher in primary tumors with higher Clark level $(P=0.007, \quad r=0.32)$ and with increasing tumor thickness according to Breslow $(P=0.001$; $r=0.32$ ). No significant correlation between expression of Bax, Bcl-2, Bcl-2/Bax ratio, and Clark levels or tumor thickness according to Breslow was found.

\section{Relation between Expression of CD10, Ki-67, Bcl-2, and Bax}

Results are summarized in Tables 4 and 5. Ki-67 expression positively correlated with CD10 expres- sion in melanoma cells $(P=0.01, r=0.26)$ as well as in fibroblast-like cells forming peritumoral cuff $(P=0.01, r=0.33)$. There was a negative correlation between expression of Ki67 and Bcl-2 $(P=0.02$, $r=0.23$ ). Also, Bcl-2 expression had negative correlation with CD10 expression in melanoma cells $(P=0.04, r=0.21)$ and intratumoral fibroblast-like stromal cells $(P=0.04, \quad r=0.26)$. Bax positively correlated with CD10 expression in melanoma cells only $(P=0.03, r=0.22)$.

\section{Differences between Primary and Metastatic Melanoma}

The results are summarized in Table 6 . At $10 \%$ cutoff point, $61 \%(11 / 28)$ metastatic tumors expressed CD10. The level of CD10 expression (Figure 3a, $P=0.01$ ) and Ki-67 expression (Figure $3 \mathrm{~b}$, $P=0.02$ ) were significantly higher in metastatic than primary tumors (Figure 1c and d). However, Bcl-2 had higher expression in the primary melanoma (Figure 3a, $P=0.02$ ). Similarly, Bcl-2/Bax ratio was higher in the primary tumors $(P=0.006)$.

\section{CD10, Bcl-2, and Bax Expression in Benign Looking Skin}

In the normal looking skin surrounding tumors, CD10 immunoreactivity was seen in hair follicles,

Table 3 Primary melanoma size and' immunophenotype

\begin{tabular}{lcc}
\hline & Clark levels & $\begin{array}{c}\text { Tumor thickness/ } \\
\text { Breslow }\end{array}$ \\
\hline CD10 & & \\
$\quad$ Tumor cells & $P=0.03, r=0.27$ & $P=0.02, r=0.29$ \\
Intratumoral stromal & $P=0.04$ & $P=0.01, r=0.33$ \\
cells & & $\mathrm{NS}$ \\
$\begin{array}{l}\text { Peritumoral stromal } \\
\text { cells }\end{array}$ & $\mathrm{NS}$ & \\
Ki-67 & $P=0.007, r=0.32$ & $P=0.001, r=0.30$ \\
Bcl-2 & $\mathrm{NS}$ & $\mathrm{NS}$ \\
Bax & $\mathrm{NS}$ & $\mathrm{NS}$ \\
Bcl-2/Bax & $\mathrm{NS}$ & $\mathrm{NS}$ \\
\hline
\end{tabular}

${ }^{\mathrm{a}}$ Spearman rank correlation test except for the analysis of the content of CD10+ intratumoral and peritumoral stromal cells in relation to Clark levels, for which linear-by-linear association test was used. $\mathrm{NS}=$ not significant

Table 2 CD10, Bcl-2 and Bax H-score distribution

Histo-score

Total

\begin{tabular}{|c|c|c|c|c|c|c|c|c|c|c|}
\hline & \multicolumn{3}{|c|}{ CD10 } & \multicolumn{3}{|c|}{$B c l-2$} & \multicolumn{3}{|c|}{$\operatorname{Bax}$} & \\
\hline & Low & Intermediate & High & Low & Intermediate & High & Low & Intermediate & High & \\
\hline Primary melanoma (\%) & $35(50)$ & $22(31)$ & $13(19)$ & $13(19)$ & $12(17)$ & $44(64)$ & 0 & 13 (19) & $57(81)$ & $70(100)$ \\
\hline Metastatic melanoma (\%) & $10(36)$ & $4(14)$ & $14(50)$ & $13(46)$ & 3 (11) & $12(43)$ & $1(4)$ & $2(7)$ & $25(89)$ & $28(100)$ \\
\hline
\end{tabular}

\footnotetext{
${ }^{\mathrm{a}}$ Low (0-100), intermediate (101-200), high (201-300).
} 
a
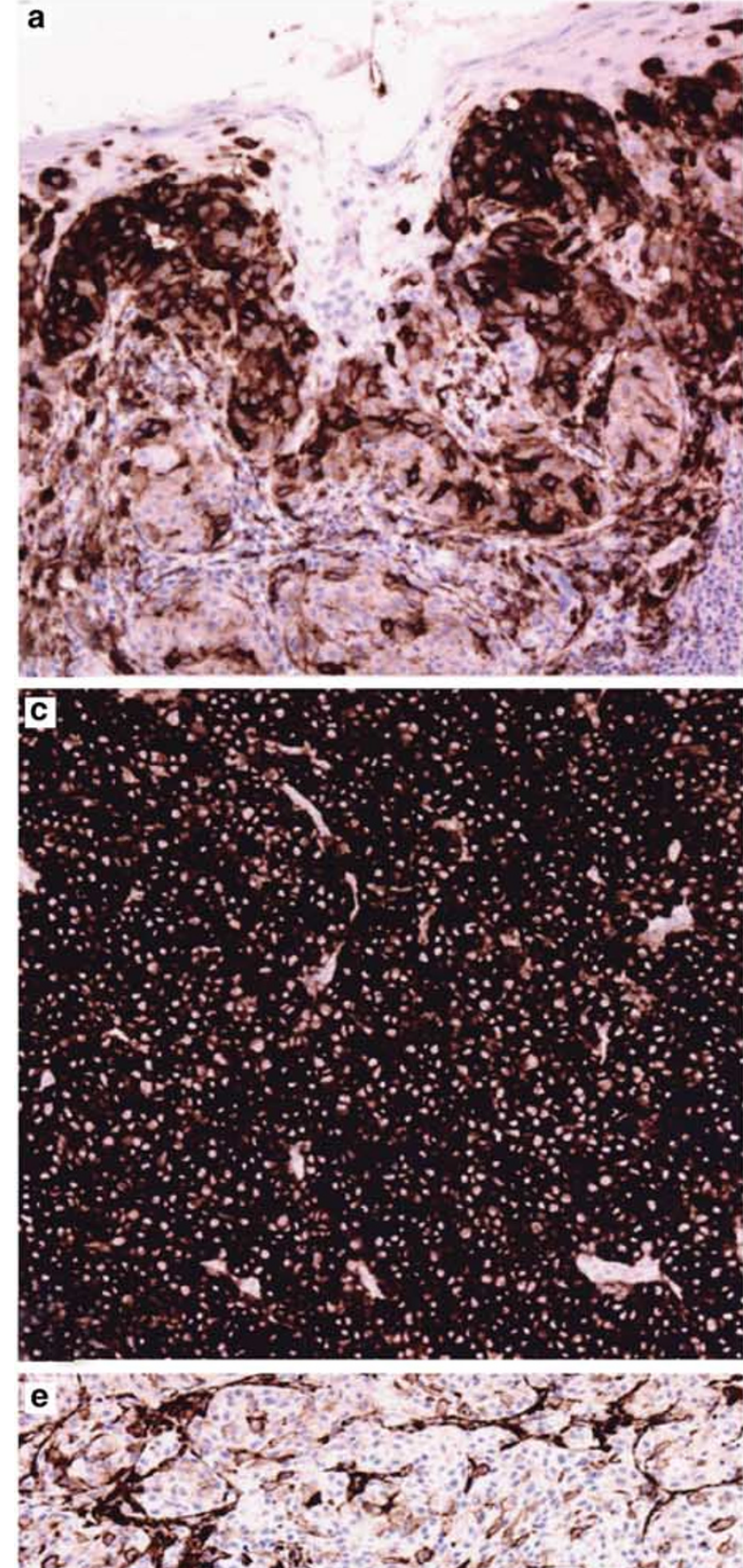

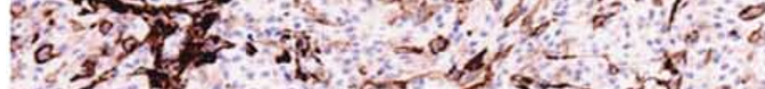

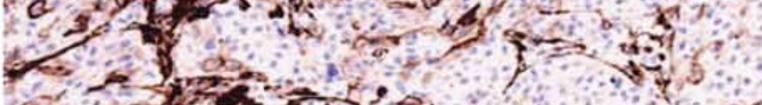

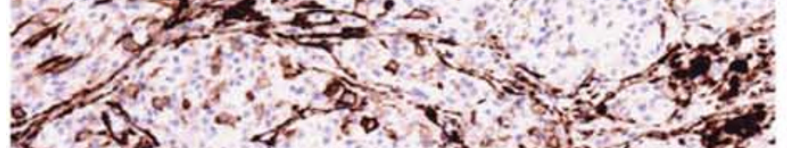

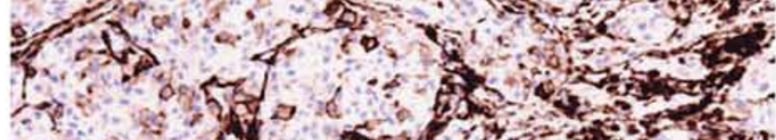

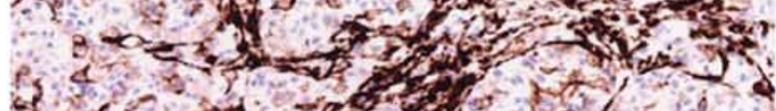

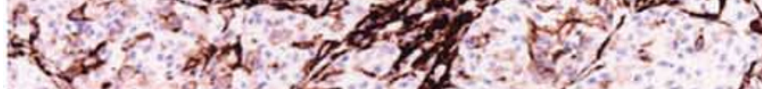

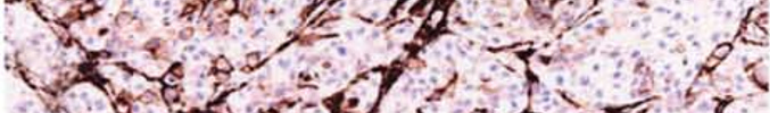
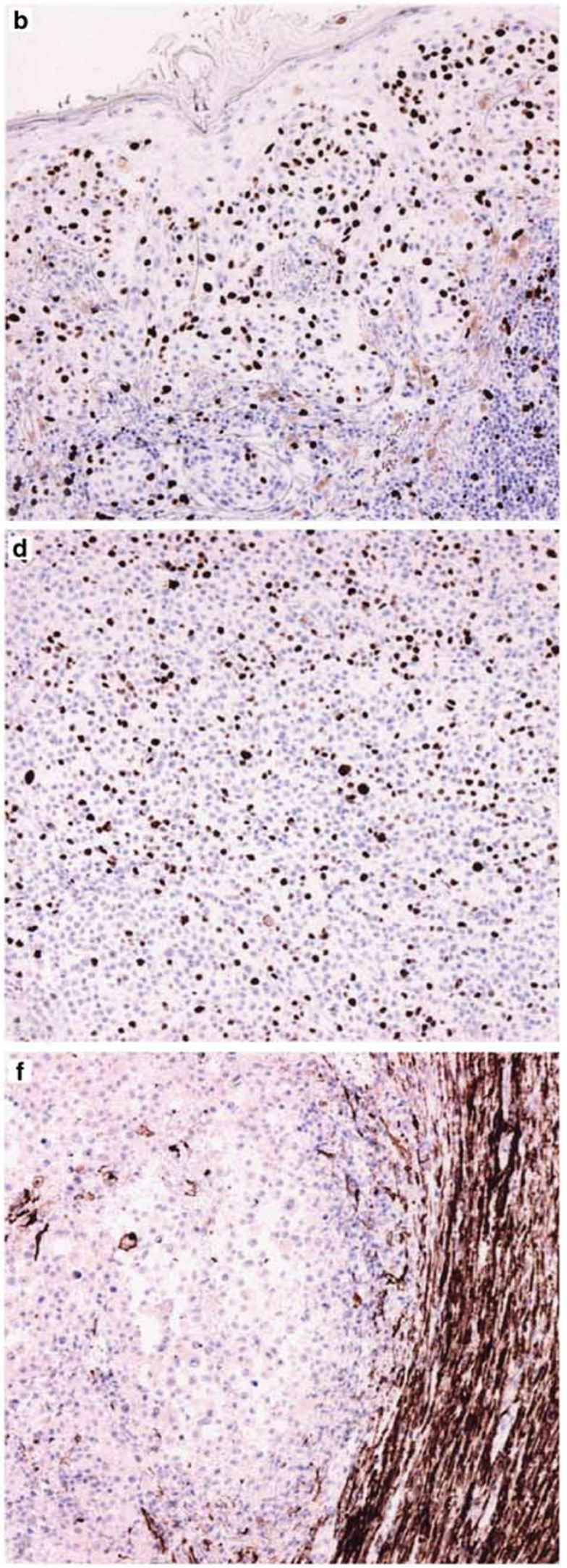
eccrine and sebaceous glands as well as in endothelium of blood vessels, large nerves, and generally scant slender fibroblast-like cells in the dermis. In the normal epidermis, Bcl-2 expression was confined to basal keratinocytes that exhibited cytoplasmic staining with perinuclear enhancement. The suprabasal keratinocytes uniformly were Bcl-2 negative. Bcl-2 reacted strongly with scattered melanocytes in the basal layer of the skin and the hair matrix. Lymphocytes in the dermis and epidermis also expressed Bcl-2. The proapoptotic Bax protein was present in normal epidermis and its appendages, with the suprabasal compartment being stained more strongly than basal keratinocytes. Ki-67 positivity in normal human epidermis was mainly restricted to the suprabasal cell layers of the epidermis.

\section{Discussion}

CD10 expression has been reported in six of 15 cultured melanoma cells lines, ${ }^{32}$ in malignant melanoma of the uvea and conjunctiva ${ }^{33}$ and in cutaneous melanomas. ${ }^{3,4,9,32,33}$ Overall expression of CD10 in cutaneous melanoma is reported to be about 40-50\%. However, Carrel et $a l^{4}$ and Kanitakis et $a l,{ }^{3,34}$ found higher expression of CD10 in metastatic tumors. Carrel et $a l^{4}$ also showed that expression of CD10 is higher in primary melanomas larger than $3 \mathrm{~mm}$. Our study confirms these previous results, but also elaborates observations on CD10 expression in primary melanoma with regard to higher CD10 expression in higher Clark levels and larger Breslow thickness of the tumor. Hence, CD10 expression in melanoma cells appears to be associated with tumor progression. Interestingly, in carcinomas of the lung ${ }^{35}$ and kidney, ${ }^{36}$ expression of CD10 is downregulated in comparison with benign tissues, but CD10 expression was evaluated only in primary tumors and was not compared to CD10 expression in metastatic lesions.

Even though the exact role of CD10 is currently not known, our study suggests that CD10 expression in malignant melanoma significantly correlates with

Figure 1 Only rare primary melanomas had strong expression of CD10 (anti-CD10, magnification $\times 100)(a)$. Such cases were associated with much higher proliferation rate than CD10negative primary melanomas (anti-Ki-67, magnification $\times 100$ ) (b). The strongest expression of CD10 was found in metastatic melanomas, particularly those metastatic to lymph nodes (antiCD10, $\times 100)(\mathbf{c})$. Metastatic melanomas with strong CD10 expression also had higher proliferation rate than those with weak or no CD10 expression (anti-Ki-67, magnification $\times 100)(\mathbf{d})$. The content of intratumoral (e) and peritumoral (f) CD10-positive fibroblast-like cells in primary tumors positively correlated with higher Clark levels and thickness of the tumor according to Breslow (Clark level 4, thickness $3.40 \mathrm{~mm}$ for intratumoral $\mathrm{CD} 10+$ cells and Clark level 4 , thickness $3.55 \mathrm{~mm}$ for peritumoral CD10 + fibroblast-like cells) (anti-CD10, × 100).
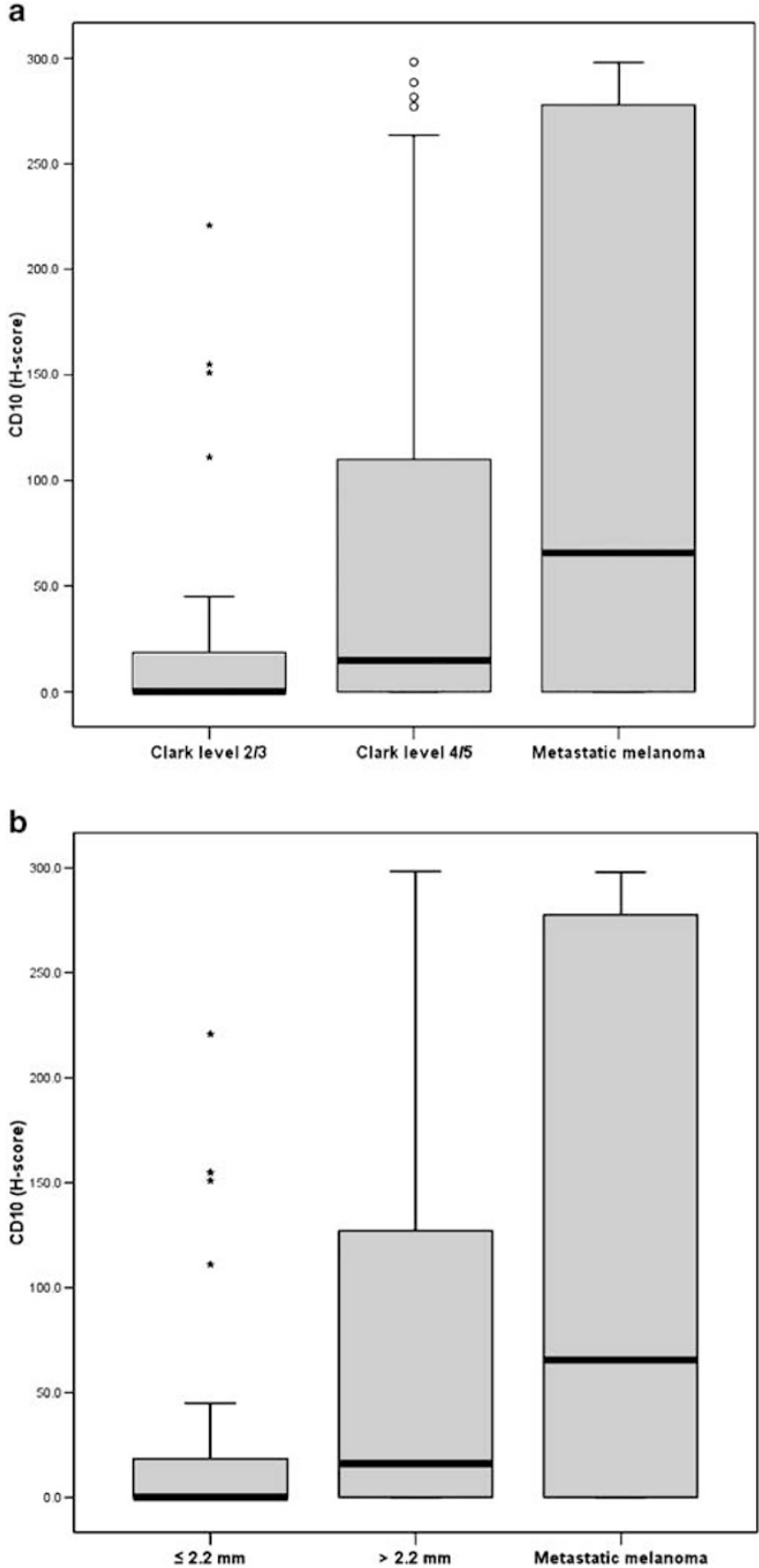

Figure 2 (a) CD10 expression is higher in higher Clark levels (4 and 5) than in lower Clark levels (2 and 3). Also, metastatic tumors express more CD10 than primary tumors. (b) Primary melanomas with thickness $\leq 2.2 \mathrm{~mm}$ (thickness median) also have lower expression of CD10 than primary tumors $>2.2 \mathrm{~mm}$. The horizontal line inside the box represents the median. The outliers are cases with the values between 1.5 and 3 box-lengths from the 75th percentile or 25th percentile. The extreme values are cases with the values more than 3 box-lengths from the 75th or 25th percentile.

increased proliferation of melanoma cells. Recently, an association between CD10 expression and increased proliferation was found in diffuse large Bcell lymphoma by Bai et al. ${ }^{37}$ In the same study, the 
Table 4 CD10 correlation with markers of proliferation and apoptosis

\begin{tabular}{lccc}
\hline & \multicolumn{3}{c}{ CD10 } \\
\cline { 2 - 4 } & Tumor cells & $\begin{array}{c}\text { Intratumoral } \\
\text { stromal cells }\end{array}$ & $\begin{array}{c}\text { Peritumoral } \\
\text { stromal cells }\end{array}$ \\
\hline Ki-67 & $P=0.01, r=0.26$ & NS & $P=0.01, r=0.33$ \\
Bcl-2 & $P=0.04, r=0.21$ & $P=0.04, r=0.26$ & NS \\
Bax & $P=0.03, r=0.22$ & NS & NS \\
Bcl-2/Bax & NS & $P=0.06, r=0.23$ & NS \\
\hline
\end{tabular}

NS $=$ not significant

Table 5 Correlation between expression of Ki67, Bcl-2, and Bax

\begin{tabular}{lc}
\hline & Ki-67 \\
\hline Bax & NS \\
Bcl-2 & $P=0.02, r=0.23$ \\
Bcl-2/Bax & $P=0.02, r=0.25$
\end{tabular}

$\mathrm{NS}=$ not significant

Table 6 Relationship between expression CD10, Ki-67, Bax, Bcl2/Bax ratio in primary vs metastatic tumors using the MannWhitney $U$ analysis

\section{Primary vs metastatic melanoma}

\begin{tabular}{lc}
\hline CD10 (tumor cells) & $P=0.01$ \\
Ki-67 & $P=0.02$ \\
Bcl-2 & $P=0.02$ \\
Bax & NS \\
Bcl-2/Bax ratio & $P=0.006$
\end{tabular}

NS $=$ not significant

authors also found that CD10 expression was associated with higher apoptotic index. We have not investigated the apoptotic index in our study, but observed that CD10 expression had a negative correlation with Bcl-2 expression and a positive correlation with Bax expression, which is in accordance with the results observed by Bai et al. ${ }^{37}$ Our findings that Bcl-2 is more expressed in primary than in metastatic melanomas and that Bcl-2 has an inverse correlation with proliferation fraction are in accordance with previous reports. ${ }^{38,39} \mathrm{Bcl}-2$ is best known for its function as an antiapoptotic protein, but Liang et $a l^{40}$ just reported that Bcl-2 mediates induction of neural differentiation and decreases expression of several proliferation-related genes in PC12 neural crest tumor cells. Accordingly, it may be plausible that loss of Bcl-2 expression in malignant melanoma may reflect loss of differentiation. Further studies are needed to investigate this possibility. Interestingly, such relationship between degree of cell differentiation and proliferation is also a
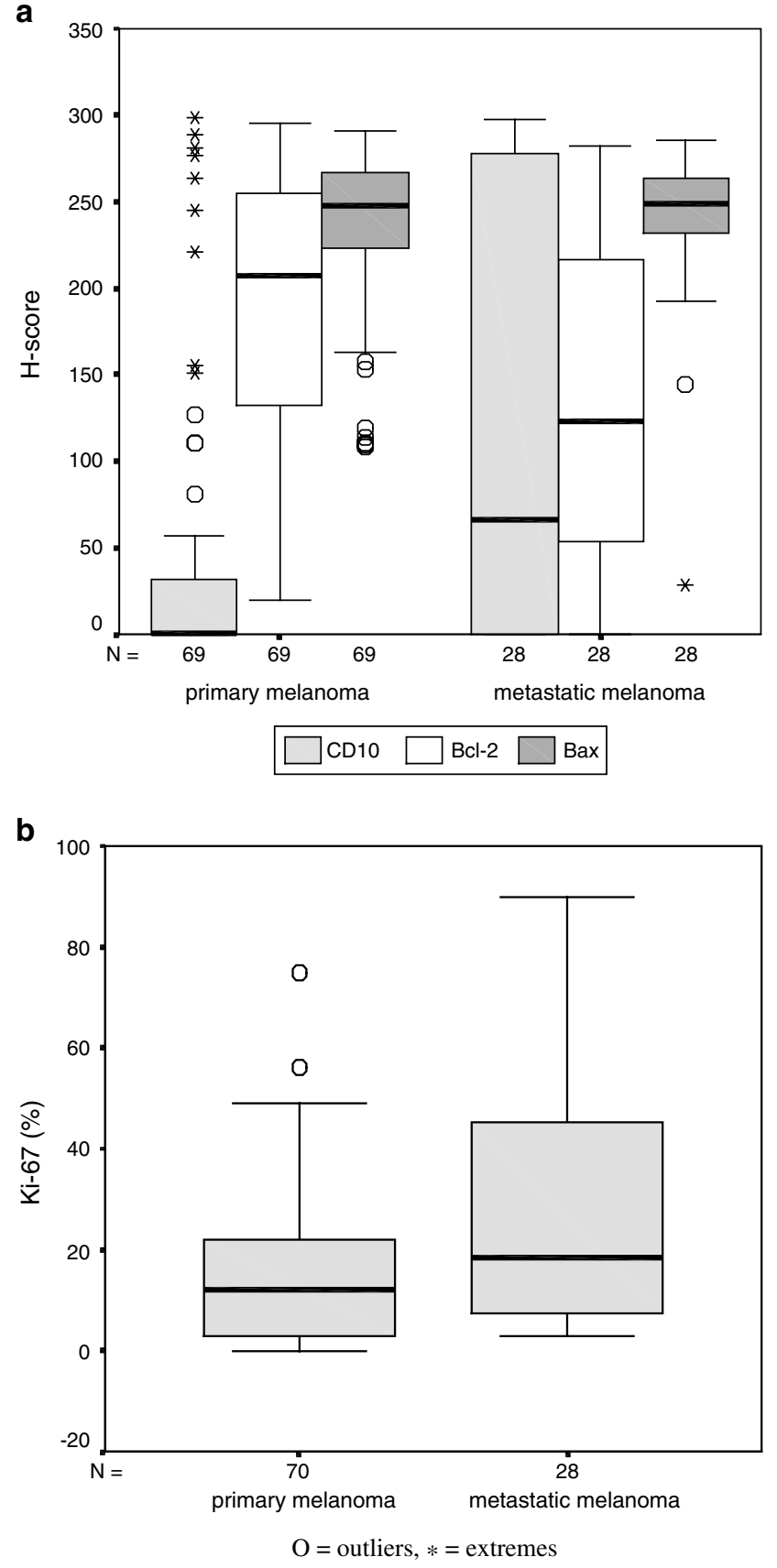

Figure 3 CD10 expression is higher in the metastatic melanoma $(P=0.01)$, but Bcl-2 is more expressed in the primary $(P=0.02)$. No difference was found for Bax expression (a). The percent of Ki67-positive cells is higher in metastatic than primary melanomas $(P=0.02)(b)$. The horizontal line inside the box represents the median. The outliers are cases with the values between 1.5 and 3 box-lengths from the 75th or 25th percentile. The extreme values are cases with the values more than 3 box-lengths from the 75th or 25th percentile.

reported in lymphoid tissues. Low-grade follicular lymphomas regularly express high levels of Bcl-2 and have very low proliferation rate, while grade 3 follicular lymphomas frequently have low or no expression of Bcl-2 and also have generally higher proliferation rate. ${ }^{41-43}$ 
The invasive and/or metastatic potential of several types of cancer cells is regulated by interactions with stromal cells, which involve stimulatory and inhibitory factors that regulate such functions as cellular adhesion, migration, and gene expression. ${ }^{4-46}$ It was postulated that due to structural similarities of CD10 to matrix metalloproteinases (MMPs), CD10 could create a microenvironment that facilitates cancer cell invasion and metastasis. ${ }^{47,48}$ The role of CD10 expression in benign stromal cells was so far investigated only in breast carcinoma. Iwaya et $a l^{18}$ showed that CD10 is expressed by the stromal cells within the area of invasive ductal carcinoma, but not in the stromal cells of normal breast or noninvasive carcinoma. Our observation that CD10 is expressed in stromal cells of more advanced primary melanomas and their association with higher proliferation rate suggests that stromal cells may also have an important role in progression of malignant melanoma.

In conclusion, more advanced melanomas express more CD10, both in melanoma cells and fibroblastlike stromal cells.

\section{Acknowledgements}

This study was partly funded by the Norwegian Cancer Society and Research Council of Norway.

\section{References}

1 Ilmonen S, Asko-Seljavaara S, Kariniemi AL, et al. Prognosis of primary melanoma. Scand J Surg 2002;91:166-171.

2 Marghoob AA, Koenig K, Bittencourt FV, et al. Breslow thickness and Clark level in melanoma: support for including level in pathology reports and in American Joint Committee on Cancer Staging. Cancer 2000;88:589-595.

3 Kanitakis J, Narvaez D, Claudy A. Differential expression of the CD10 antigen (neutral endopeptidase) in primary versus metastatic malignant melanomas of the skin. Melanoma Res 2002;12:241-247.

4 Carrel S, Zografos L, Schreyer M, et al. Expression of CALLA/CD10 on human melanoma cells. Melanoma Res 1993;3:319-323.

5 Metzgar RS, Borowitz MJ, Jones NH, et al. Distribution of common acute lymphoblastic leukemia antigen in nonhematopoietic tissues. J Exp Med 1981;154: 1249-1254.

6 Gusterson BA, Monaghan P, Mahendran R, et al. Identification of myoepithelial cells in human and rat breasts by anti-common acute lymphoblastic leukemia antigen antibody A12. J Natl Cancer Inst 1986;77: 343-349.

7 Sato Y, Itoh F, Hinoda Y, et al. 12-7 Expression of CD10/neutral endopeptidase in normal and malignant tissues of the human stomach and colon. J Gastroenterol 1996;31:12-17.

8 Johnson AR, Coalson JJ, Ashton J, et al. Neutral endopeptidase in serum samples from patients with adult respiratory distress syndrome. Comparison with angiotensin-converting enzyme. Am Rev Respir Dis 1985;132:1262-1267.

9 Chu P, Arber DA. Paraffin-section detection of CD10 in 505 nonhematopoietic neoplasms. Frequent expression in renal cell carcinoma and endometrial stromal sarcoma. Am J Clin Pathol 2000;113:374-382.

10 Notohara K, Hamazaki S, Tsukayama C, et al. Solidpseudopapillary tumor of the pancreas: immunohistochemical localization of neuroendocrine markers and CD10. Am J Surg Pathol 2000;24:1361-1371.

11 Shipp MA, Look AT. Hematopoietic differentiation antigens that are membrane-associated enzymes: cutting is the key!. Blood 1993;82:1052-1070.

12 Kondepudi A, Johnson A. Cytokines increase neutral endopeptidase activity in lung fibroblasts. Am J Respir Cell Mol Biol 1993;8:43-49.

13 van der Velden VHJ, Naber BAE, van der Spoel P, et al. Cytokines and glucocorticoids modulate human bronchial epithelial cell peptidases. Cytokine 1998;10:5565.

14 Papandreou CN, Usmani B, Geng Y, et al. Neutral endopeptidase 24.11 loss in metastatic human prostate cancer contributes to androgen-independent progression. Nat Med 1998;4:50-57.

15 Cutrona G, Leanza N, Ulivi M, et al. Expression of CD10 by human T cells that undergo apoptosis both in vitro and in vivo. Blood 1999;94:3067-3076.

16 Sumitomo M, Shen R, Goldberg JS, et al. Neutral endopeptidase promotes phorbol ester-induced apoptosis in prostate cancer cells by inhibiting neuropeptide-induced protein kinase C-degradation. Cancer Res 2000;60:6590-6596.

17 Suzuki T, Ino K, Kikkawa F, et al. Neutral endopeptidase/CD10 expression during phorbol ester-induced differentiation of choriocarcinoma cells through the protein kinase C- and extracellular signal-regulated kinase-dependent signaling pathway. Placenta 2002; 23:475-482.

18 Iwaya K, Ogawa H, Izumi M, et al. Stromal expression of CD10 in invasive breast carcinoma: a new predictor of clinical outcome. Virchows Arch 2002;440:589-593.

19 Thompson CB. Apoptosis in the pathogenesis and treatment of disease. Science 1995;267:1456-1462.

20 Ellis RE, Yuan J, Horvitz HR. Mechanisms and functions of cell death. Annu Rev Cell Biol 1991; 7:663-698.

21 Korsmeyer SJ. Bcl-2 initiates a new category of oncogenes: regulator of cell death. Blood 1992;80: 879-886.

22 Chao DT, Korsmeyer SJ. Bcl-2 family: regulators of cell death. Annu Rev Immunol 1998;16:395-419.

23 Boise LH, Thompson CB. Bcl-x (L) can inhibit apoptosis in cells that have undergone Fas-induced protease activation. Proc Natl Acad Sci USA 1997;94: 3759-3764.

24 Tron VA, Krajevski S, Klein-Parker H, et al. Immunohistochemical analysis of Bcl-2 protein regulation in cutaneous melanoma. Am J Pathol 1995;146:643-650.

25 Seizer E, Schlagbauer-Wadl H, Okamoto I, et al. Expression of Bcl-2 family members in human melanocytes, in melanoma metastases and in melanoma cell lines. Melanoma Res 1998;8:197-203.

26 Ramsay JA, From L, Iscoe NA, et al. MIB-1 proliferative activity is a significant prognostic factor in primary thick cutaneous melanomas. J Invest Dermatol 1995; 105:22-26. 
27 Grover R, Wilson GD. Bcl-2 Expression in malignant melanoma and its prognostic significance. Eur J Surg Oncol 1996;22:347-349.

28 Tang L, Tron VA, Reed JC, et al. Expression of apoptosis regulators in cutaneous malignant melanoma. Clin Cancer Res 1998;4:1865-1871.

29 Loggini B, Rinaldi I, Pingitore R, et al. Immunohistochemical study of 49 cutaneous melanomas: p53, PCNA, Bcl-2 expression and multidrug resistance. Tumori 2001;87:179-186.

30 Leiter U, Schmid RM, Kaskel P, et al. Antiapoptotic Bcl-2 and bcl-xL in advanced malignant melanoma. Arch Dermatol Res 2000;292:225-232.

31 McCarty Jr KS, Miller LS, Cox EB, et al. Use of a monoclonal anti-estrogen receptor antibody in the immunohistochemical evaluation of human tumors. Arch Pathol Lab Med 1985;109:716-721.

32 Carrel S, Schmidt-Kessen A, Mach JP, et al. Expression of common acute lymphoblastic leukemia antigen (CALLA) on human malignant melanoma cell lines. J Immunol 1983;130:2456-2460.

33 Carrel S, Schreyer M, Gross N, et al. Surface antigenic profile of uveal melanoma lesions analyzed with a panel of monoclonal antibodies directed against cutaneous melanoma. Anticancer Res 1990;10: 81-89.

34 Kanitakis J, Bourchany D, Claudy A. Expression of the CD10 antigen (neutral endopeptidase) by mesenchymal tumors of the skin. Anticancer Res 2000;20: 3539-3544.

35 Shipp MA, Tarr GE, Chen CY, et al. CD10/neutral endopeptidase 24.11 hydrolyzes bombesin-like peptides and regulates the growth of small cell carcinomas of the lung. Proc Natl Acad Sci USA 1991;88: 10662-10666.

36 Gohring B, Holzhausen HJ, Meye A, et al. Endopeptidase $24.11 / \mathrm{CD} 10$ is down-regulated in renal cell cancer. Int J Mol Med 1998;2:409-414.

37 Bai M, Agnantis NJ, Skyrlas A, et al. Increased Expression of the Bcl6 and CD10 proteins is associated with increased apoptosis and proliferation in diffuse large B-cell lymphomas. Mod Pathol 2003;16: 471-480.
38 Vlaykova $\mathrm{T}$, Talve L, Hahka-Kemppinen $\mathrm{M}$, et al. Immunohistochemically detectable Bcl-2 expression in metastatic melanoma: association with survival and treatment response. Oncology 2002;62:259-268.

39 Sviatoha V, Rundgren A, Tani E, et al. Expression of CD40, CD44, Bcl-2 antigens and rate of cell proliferation on fine needle aspirates from metastatic melanoma. Cytopathology 2002;13:11-21.

40 Liang Y, Mirnics ZK, Yan C, et al. Bcl-2 mediates induction of neural differentiation. Oncogene 2003;22: $5515-5518$

41 Lai R, Arber DA, Chang KL, et al. Frequency of Bcl-2 expression in non-Hodgkin's lymphoma: a study of 778 cases with comparison of marginal zone lymphoma and monocytoid B-cell hyperplasia. Mod Pathol 1998;11:864-869.

42 Ngan BY, Chen-Levy Z, Weiss LM, et al. Expression in non-Hodgkin's lymphoma of the Bcl-2 protein associated with the $t(14 ; 18)$ chromosomal translocation. N Engl J Med 1988;318:1638-1644.

43 Lawnicki LC, Weisenburger DD, Aoun P, et al. The $t(14 ; 18)$ and Bcl-2 expression are present in a subset of primary cutaneous follicular lymphoma: association with lower grade. Am J Clin Pathol 2002;118:765-772.

44 Bemis LT, Schedin P. Reproductive state of rat mammary gland stroma modulates human breast cancer cell migration and invasion. Cancer Res 2000;60:3414-3418.

45 Sternlicht MD, Locaters A, Sympson CJ, et al. The stromal proteinase MMP3/stromelysin-1 promotes mammary carcinogenesis. Cell 1999;98:137-146.

46 Tran NL, Nagle RB, Cress AE, et al. N-Cadherin expression in human prostate carcinoma cell lines. An epithelial-mesenchymal transformation mediating adhesion with stromal cells. Am J Pathol 1999; 155:787-798.

47 Basset P, Wolf C, Rouyer N, et al. Stromelysin-3 in stromal tissue as a control factor in breast cancer behavior. Cancer 1994;74:1045-1049.

48 Talvensaari-Mattila A, Paakko P, Hoyhtya M, et al. Matrix metalloproteinase-2 immunoreactive protein: a marker of aggressiveness in breast carcinoma. Cancer 1998;83:1153-1162. 